\title{
Análise de indicadores de desempenho para a mensuração da produtividade dos profissionais de assessoria executiva
}

\author{
Analysis of performance indicators for measuring the productivity of executive \\ assistant professionals
}

\section{Daianna Costa Flores Beloํ, Maria Vilma de Lima² e Bárbara Ilze Semensato}

\footnotetext{
${ }^{1}$ Fundação Escola de Comércio Álvares Penteado, Brasil, Especialista Assessoria Executiva, e-mail: daia.belo@gmail.com ${ }^{2}$ Fundação Escola de Comércio Álvares Penteado, Brasil, Especialista Assessoria Executiva, e-mail: mvilma.lima09@gmail.com

${ }^{3}$ Fundação Escola de Comércio Álvares Penteado, Brasil, Doutorado em Administração, e-mail: barbarailze@gmail.com
}

Recebido em: 08/03/2019 - Aprovado em: 02/04/2019 - Disponível em: 01/07/2019

\section{Resumo}

Este relato técnico visa apresentar um instrumento de pesquisa para a mensuração da produtividade dos profissionais de assessoria executiva, a partir do estudo de indicadores de desempenho, tendo como base a teoria do Balanced Scorecard. A explicação sobre os indicadores de desempenho visa identificar, de forma clara e objetiva, como a implantação de indicadores de desempenho específicos para os profissionais de assessoria executiva pode contribuir na mensuração de sua produtividade, bem como elevar o seu desempenho. Com isso, pode-se analisar como esses profissionais podem contribuir, por meio de suas competências essenciais, para o alcance dos objetivos estratégicos das empresas. $\mathrm{O}$ instrumento de pesquisa apresenta questões abertas (discursivas) visando contribuir com o desenvolvimento de indicadores que possam mensurar o desempenho destes profissionais, dando um norte para o desenvolvimento de um sistema de mensuração, bem como para o desenvolvimento de futuros estudos sobre o tema.

Palavras-chave: Balanced Scorecard. Indicadores de Desempenho. Assessoria Executiva.

\begin{abstract}
This technical report aims to present a research instrument to measure the productivity of executive assistant professionals, based on the study of performance indicators, based on the theory of the Balanced Scorecard. The explanation about the performance indicators aims to identify, in a clear and objective way, how the implementation of specific performance indicators for the executive assistant professionals can contribute to the measurement of their productivity, as well as to increase their performance. In this sense, it is possible to analyze how these professionals can contribute, through their core competences, to reach the strategic objectives of the organizations. The research instrument presents open (discursive) questions
\end{abstract}


aiming to contribute to the development of indicators that can measure the performance of these professionals, giving the direction to the development of a measurement system, as well as for the development of future studies on the subject.

Keywords: Balanced Scorecard. Performance Indicators. Executive Assistant.

\section{Introdução}

Este relato técnico visa apresentar uma proposição de um instrumento de pesquisa para a mensuração da produtividade dos profissionais de assessoria executiva, a partir do estudo de indicadores de desempenho. Kaplan e Norton (1997) fornecem a base teórica para esta análise, ao apresentar o Balanced Scorecard (BSC), um instrumento de mensuração de desempenho que visa observar todas as atividades do negócio, focando nas mais importantes. O ponto principal deste relato técnico é demonstrar como as competências exercidas no dia-a-dia dos profissionais de assessoria executiva podem contribuir no alcance das metas corporativas, além de promover sua participação efetiva, permitindo que se sintam parte do processo produtivo. Conforme afirmam Kaplan e Norton (2004a, p. 16): “As empresas devem empenhar-se em identificar e mensurar suas competências essenciais, as tecnologias críticas necessárias para assegurar a liderança de mercado contínua. Além disso, é preciso que definam os processos e competências em que serão excelentes e especifiquem os respectivos indicadores."

Mudanças na profissão trouxeram novas oportunidades e desafios aos profissionais de assessoria executiva e, consequentemente, a ampliação da sua área de atuação, obrigando-os a desenvolver novas habilidades como: gestão de metas e objetivos, polivalência, agilidade, aptidão para a realização de diferentes tarefas, administração de conflito e compreensão do fator humano (D’ELIA; NEIVA 2009). Nas palavras de Marinho (2014), para atender essa demanda é necessário que este profissional desenvolva competências como: visão estratégica, comunicação e relacionamento interpessoal.

Porém, mesmo com as mudanças ocorridas no mercado, percebe-se que ainda não há consenso se, na posse dessas competências, esses profissionais estão aptos para contribuir na concretização de ações relativas às estratégias advindas da alta administração. Por isso, há um movimento incipiente de profissionais da classe na busca pela transformação dessa realidade. Nas palavras de Kaplan e Norton (2004a, p. 7) "o que é medido é conseguido"; porém a maior parte das empresas não considera os assessores executivos como parte importante neste contexto, mesmo sabendo que a implantação de indicadores em todas as áreas da companhia impulsiona seu crescimento.

Este fenômeno ocorre por ainda existir questionamentos equivocados e distorcidos acerca da profissão, conforme afirma Ortega (2013, p. 111) “crença que suas atividades são simplistas, corriqueiras e impossíveis de serem mensuradas ou atreladas às diretrizes estratégicas". A inexistência de estudos específicos, bem como de parâmetros para medir seus resultados, causa prejuízo em seu desempenho e desencadeia fatores negativos como: desmotivação, falta de efetividade e notoriedade de sua atuação no meio corporativo. Por isso, pela ótica da área de assessoria executiva, gerar resultados e poder mensurá-los é um desafio (D'ELIA, 2013). 
Desta forma, para melhor entendimento da necessidade e aplicabilidade dos indicadores de desempenho, o BSC é utilizado como base deste estudo. O objetivo é traduzir a importância do uso de indicadores de desempenho para a mensuração da produtividade dos profissionais de assessoria executiva na forma de um instrumento de pesquisa. Este estudo visa agregar visibilidade à atuação deste profissional, e contribuir para a geração de dados concretos que possam mensurar seus resultados, uma vez que é uma constante exigência no mercado atual. $\mathrm{O}$ intuito dos modelos de mensuração é motivar executivos e colaboradores a implementarem com êxito a estratégia do negócio (KAPLAN; NORTON, 1997).

\section{Contexto e Realidade Investigada}

A mensuração da produtividade dos profissionais de assessoria executiva através de indicadores de desempenho visa nortear como o trabalho desenvolvido por estes profissionais gera valor e resultado para as organizações. Os indicadores de desempenho possuem métricas que permitem mensurar a produtividade, a efetividade do trabalho desempenhado e o atingimento de metas e objetivos organizacionais. Desta forma, compreender e entender como os indicadores de desempenho operam é importante para a sua correta aplicação.

Um sistema de medição de desempenho associa variáveis internas e externas da organização às estratégias e ao sistema de informação. Este sistema reúne um conjunto de métodos e procedimentos para gerar, analisar e expor, descrever e avaliar dados e informações sobre múltiplas dimensões de desempenho, de pessoas, grupos e níveis organizacionais (PONGELUPPE, 2002 apud GERLACH, 2004).

Segundo Kaplan e Norton (2004a, p. 67) “à medida que as empresas em todo mundo se transformam para a competição baseada na informação, a capacidade de explorar ativos intangíveis tornou-se muito mais decisiva do que a capacidade de construir e gerenciar ativos físicos". O BSC veio para suprir esta demanda, pois se denomina em uma ferramenta de planejamento estratégico, em que a empresa, através da compreensão clara de suas metas e estratégias, é capaz de mensurar o seu desempenho, por meio de indicadores quantificáveis e verificáveis. O que diferencia o BSC de outros sistemas de mensuração não é a inexistência de medidas não financeiras, mas o fato de todas as medidas derivarem da visão e da estratégia da empresa. O BSC tem como objetivos (KAPLAN; NORTON, 1997):

1 - Esclarecer e traduzir a visão estratégica.

2 - Comunicar e associar objetivos e medidas estratégicas

3 - Planejar, estabelecer metas e alinhar iniciativas estratégicas.

4 - Melhorar o feedback e o aprendizado estratégico.

O BSC fornece uma visão ampliada de como a organização irá converter suas iniciativas e recursos, incluindo ativos intangíveis, como a cultura organizacional e as competências dos colaboradores, e o conhecimento dos resultados tangíveis previsíveis, por meio das ligações de causa e efeito (ONG, 2010).

O scorecard é uma ferramenta gerencial que busca avaliar os resultados a partir da mensuração de ativos tangíveis e intangíveis de uma organização, preservando as medidas financeiras tradicionais, mas focando também em outras três perspectivas de desempenho: clientes, processos internos e aprendizagem e crescimento (CARPINETTI, 2012). Estas 
perspectivas são inter-relacionadas e possuem o mesmo grau de importância, e é por meio delas que o BSC se consolida como um método que auxilia e dá orientações específicas e claras para que as empresas enxerguem os erros de seus negócios e a forma de corrigi-los (SEHIC-KRSLAK, 2016).

A perspectiva financeira serve de foco para as outras perspectivas, ou seja, é a estratégia de crescimento, rentabilidade e risco do negócio de acordo com a visão dos acionistas. A perspectiva do cliente busca traduzir os fatores que realmente importam para os consumidores da marca/empresa. É uma estratégia que busca identificar quem é este cliente e o valor que lhe será entregue de maneira diferenciada. Articula os objetivos e as metas para atributos como: tempo, qualidade, desempenho, serviço e preço (COSTA, 2006). Os processos internos da empresa correspondem à análise dos processos mais críticos e das competências, alinhados as duas perspectivas anteriores, a financeira e do cliente. De acordo com Costa (2006, p. 34) "é na perspectiva de processos internos que a empresa definirá o que precisa ser melhorado ou criado para atender os atributos importantes mapeados pela perspectiva do cliente".

E por fim, a perspectiva de aprendizado e crescimento "proporciona a identificação dos ativos intangíveis necessários ao exercício pleno das atividades organizacionais e das relações com os consumidores" (RESENDE, 2003, p. 103). Na perspectiva de aprendizado e crescimento estão os pilares da estratégia organizacional voltados para a sociedade do conhecimento, ou seja, as competências essenciais. Esta perspectiva oferece a infraestrutura que viabiliza a consecução das demais perspectivas (KAPLAN; NORTON, 1997).

Esta ferramenta permite aos gerentes assegurar que todos os níveis da empresa compreendam as estratégias de longo prazo e que os objetivos individuais estejam alinhados à estratégia. As unidades devem desenvolver scorecard próprios, compatíveis com a sua missão, estratégia, tecnologia e cultura. Desta forma, entende-se que uma das premissas do BSC é a integração de todos os departamentos e colaboradores, contribuindo para os mesmos objetivos, a interação entre as metas globais da empresa e as metas individuais de forma clara, assegurando que os colaboradores que estão na base da organização possam contribuir com ações, decisões e atividades de melhoria que contribuirão com as estratégias da empresa (KAPLAN; NORTON, 1997).

Paraqueas estratégias sejam efetivamenteimplementadas, énecessárioo envolvimento dos colaboradores que deverão executá-las. As organizações que desejam a contribuição de todos os seus funcionários para a efetiva execução de suas metas devem compartilhar suas visões e estratégias de longo prazo, incentivando-os ativamente a sugerir formas pelas quais a visão e estratégia possam ser alcançadas. Esse sistema de feedback e orientação engaja os funcionários no futuro da empresa e os encoraja a participar da formulação e da implementação da estratégia (KAPLAN; NORTON, 2004a).

O BSC viabiliza o alinhamento de cima para baixo, permitindo que todos na empresa, do nível hierárquico mais elevado ao mais baixo, compreendam a estratégia e como as ações individuais sustentam as metas e os planos definidos pela alta direção (KAPLAN; NORTON, 1997). Para obter o máximo de benefícios, a equipe executiva deve compartilhar sua visão e estratégia com toda a empresa, bem como com os principais atores externos. 
Comunicando a estratégia e vinculando-as às metas pessoais, o scorecard cria entendimento e um comprometimento compartilhado entre todos os integrantes da organização.

Quando todos compreenderem as metas de longo prazo da unidade de negócios, bem como a estratégia para alcançá-las, os esforços iniciais da empresa se alinham aos processos necessários de transformação. Cada indivíduo entende como sua atuação específica contribui para a realização dos objetivos da unidade de negócios (KAPLAN; NORTON, 1997).

\section{Diagnóstico da Situação-Problema e/ou Oportunidade}

Este relato técnico visa identificar as competências essenciais exigidas dos profissionais de assessoria executiva, e demonstrar a sua relevância profissional para o alcance de resultados organizacionais. Com a utilização do BSC, torna-se possível criar e implementar ferramentas que auxiliem na mensuração da produtividade destes profissionais, alinhadas às suas competências, mostrando como é possível agregar valor às organizações a curto, médio e longo prazo. Com isso, a situação-problema deste relato técnico reside na inexistência de um instrumento de mensuração da produtividade do profissional de assessoria executiva, que permita avaliá-lo de forma adequada, fazendo com que se sinta parte do planejamento estratégico da organização.

A fim deentender qual parâmetro que empresa adota na participaçãodos profissionais de assessoria executiva, e como ocorre a mensuração do seu desempenho na organização, é proposto um instrumento de mensuração da produtividade deste profissional, visando avaliar o seu desempenho e a sua participação no atingimento das metas organizacionais. Este relato técnico enfatiza a importância de se mensurar o desempenho do profissional de assessoria executiva, desenvolver uma linguagem objetiva que permita à empresa visualizar a dimensão da sua área de atuação e mensurar o seu trabalho (D’ELIA, 2013).

\section{Análise da Situação Problema e Proposta de Inovação e Intervenção}

O instrumento é composto por questões que tratam da mensuração de desempenho, tendo como base o BSC (KAPLAN; NORTON, 1997), dos profissionais de assessoria executiva, e como estes profissionais buscam desenvolver suas competências, na ânsia de atender as demandas cada vez mais exigentes do meio corporativo. Com isso, foi utilizado as estratégias do BSC (KAPLAN; NORTON, 1997), com objetivo de traduzir a produtividade do profissional de assessoria executiva em números tangíveis.

Assim, foram elaboradas questões discursivas, separadas com base nas quatro perspectivas do BSC, incluind o o mapa estratégico, levando em consideração a elaboração de um instrumento sob ótica tanto do executivo, quanto do da assessoria executiva, de forma a alinhar as duas visões e construir um instrumento conciso e fidedigno. O intuito é contribuir com o desenvolvimento de indicadores que de fato possam mensurar o desempenho destes profissionais. Essas questões visam ser um norte, que permita o desenvolvimento de um sistema de mensuração que possa trazer ganhos expressivos para a empresa e para os profissionais de assessoria executiva.

O questionário aponta e aborda indagações referentes à implementação do modelo de indicadores de desempenho, tendo como base o BSC, e demonstra como esta ferramenta contribui na transformação das estratégias organizacionais em números tangíveis, alinhado 
as expectativas, visão da empresa e do colaborador, mapeando e direcionando as ações para um único objetivo. Nesse cenário, insere o profissional de assessoria executiva, e faz com que seu papel de atuação ganhe notoriedade por meio de uma linguagem objetiva, traduzida em indicadores de desempenho.

\section{1- Perspectiva Financeira}

a) De forma geral, como é mensurado o desempenho e o alinhamento estratégico dos colaboradores da empresa? Explique.

(Esta questão pode ser aplicada para o executivo)

b) Como é mensurado o seu desempenho profissional? O gestor fornece explicações sobre esta mensuração e se está alinhado à estratégia da empresa?

(Esta questão pode ser aplicada para o profissional de assessoria executiva)

c) Em um ambiente cada vez mais competitivo, no qual as empresas necessitam aumentar sua capacidade produtiva e ganhar rentabilidade, como o BSC colabora neste aspecto, para a geração de resultado?

\section{(Esta questão pode ser aplicada para o executivo)}

De acordo com Kaplan e Norton (2004a), na era de mudanças rápidas, as empresas, com intuito de sobrevivência, buscam implementar o BSC às estratégias da organização, traduzindo os objetivos estratégicos corporativos em um conjunto de indicadores de desempenho, criando um ambiente que favoreça a integração da equipe, levando a compreensão clara das metas.

d) Como o profissional de assessoria executiva pode contribuir no gerenciamento dos custos da sua unidade de negócios? Quais ações podem ser modificadas em suas tarefas diárias, de forma a contribuir com a otimização do orçamento destinado ao seu setor?

(Esta questão pode ser aplicada tanto para o executivo, quanto para o profissional de assessoria executiva)

O BSC tem como premissa o envolvimento de todos os colaboradores no alcance dos objetivos estratégicos, conforme afirma Kaplan e Norton (2001, p. 22), "transformar a estratégia em tarefa de todos". Otimizar o orçamento da unidade resultará em ganho para empresa, que poderá investir esse recurso em outras atribuições também importantes para a empresa, como a qualificação de seus funcionários. Um profissional de assessoria executiva competente entende as necessidades tácitas do seu executivo e possui competências, sendo as mais importantes para o sucesso da empresa (GRAMIGNA, 2002).

e) Pensando na boa utilização dos recursos da empresa e na melhoria do uso de seus recursos financeiros, quais tarefas exercidas pelo executivo podem ser absorvidas pelo profissional de assessoria executiva, a fim de otimizar o tempo dele, permitindo que seu trabalho seja focado em tarefas mais estratégias para a empresa?

(Esta questão pode ser aplicada tanto para o executivo, quanto para o profissional de assessoria executiva)

Conforme afirma Franceschini e Franceschini (2017) um dos benefícios da definição de indicadores é "Motivação dos Funcionários", que mostra aos colaboradores a importância de sair da "zona de conforto", movê-los por meio de ações que demonstrem o que eles poderão ganhar com as melhorias realizadas na empresa. $O$ profissional de assessoria 
executiva precisa entender sua posição na empresa, a importância de sua atuação para o alcance das metas corporativas, sendo hoje sua atuação muito mais estratégica. Assim, ao sair da zona de conforto, e assumir uma maior responsabilidade, ele apoiará melhor seu executivo e poderá conhecer e medir o próprio desempenho, comparar seus resultados, identificar pontos de melhoria e empreender ações de transformação pessoais, gerando um ciclo de mudanças profundas, que estimulará sua criatividade, além de permitir que se desenvolva e compartilhe aprendizados, agregando assim valor às pessoas e à organização (BOOG; BOOG, 2002).

\section{2- Perspectiva de Clientes}

a) Se você fosse cliente da empresa, o que poderia sugerir para aumentar a sua satisfação e encantamento?

(Esta questão pode ser aplicada tanto para o executivo, quanto para o profissional de assessoria executiva)

b) O cliente externo da empresa é encantado com o produto ou serviço que recebe?

(Esta questão pode ser aplicada tanto para o executivo, quanto para o profissional de assessoria executiva)

A empresa deve buscar constantemente a excelência de seus produtos e serviços, visando fidelizar seus clientes e alcançar bons resultados financeiros no mercado em que atua, conforme apresentado na definição dos objetivos dos indicadores de desempenho na perspectiva do cliente, pois sua função é traduzir os fatores que realmente importam para os consumidores da marca/empresa. É uma estratégia que busca identificar quem é este cliente e o valor a ser entregue a ele de maneira diferenciada. Articula os objetivos e as metas para atributos como: tempo, qualidade, desempenho, serviço e preço (COSTA, 2006).

c) Pensando no cliente interno, como o profissional de assessoria executiva pode melhorar a qualidade do seu atendimento? Quais ações são necessárias para que os colaboradores da empresa se sintam confiantes em transmitir informações importantes a serem resolvidas junto ao executivo?

(Esta questão pode ser aplicada tanto para o executivo, quanto para o profissional de assessoria executiva)

O profissional de assessoria executiva atua como uma ponte entre os colaboradores e seu executivo, sendo que desta forma a qualidade do seu atendimento fará toda a diferença. Os funcionários que dependem diretamente dos seus serviços precisam sentir-se confiantes para demandar-lhe tarefas e passar-lhe informações que contribuirão para a melhoria do trabalho do seu executivo. Conforme afirma Marinho (2014), a mensagem transmitida ao receptor deve estar de acordo com a linguagem corporativa, clara e objetiva, uma vez que este profissional interage com todos os níveis organizacionais.

d) Qualé a importância do treinamento dos colaboradores no que tange a disseminação de diretrizes, tais como o negócio da empresa, sua visão de mercado, metas e objetivos?

(Esta questão pode ser aplicada tanto para o executivo, quanto para o profissional de assessoria executiva) 


\section{3- Perspectiva de Processos Internos}

a) Com os processos e ações desempenhados pelo profissional de secretariado ou de assessoria executiva contribuem para o alcance de metas corporativas e como este profissional pode ser inserido no sistema de mensuração de desempenho da empresa?

(Esta questão pode ser aplicada tanto para o executivo, quanto para o profissional de assessoria executiva)

Segundo Kaplan e Norton (1997), o BSC viabiliza o alinhamento de cima para baixo, permitindo que todos na empresa, do nível hierárquico mais elevado ao mais baixo, compreendam a estratégia e como as ações individuais sustentam as metas e os planos definidos pela alta direção. Kaplan e Norton afirmam (2004a) que os gestores precisam desenvolver indicadores que possam ser influenciados pelas ações dos empregados, salientando a importância de estabelecer indicadores que se conectem a avaliação da alta administração sobre os principais processos e competências internas às ações individuais que afetam os objetivos gerais da empresa, ambiente este onde o assessor executivo atua diretamente. Por esta razão definir, uma metodologia específica de mensuração de desempenho para este profissional se torna crucial, pois a ausência desta o impacta negativamente, desfavorecendo o seu aproveitamento para o alcance de metas corporativas (D’ELIA, 2013).

b) Como o profissional de assessoria executiva pode contribuir para a padronização dos processos da empresa? Quais vícios de trabalho podem ser evitados?

(Esta questão pode ser aplicada tanto para o executivo, quanto para o profissional de assessoria executiva)

Entende-se que a padronização busca submeter os processos da empresa a um determinado modelo, buscando a sua normatização e organização, visando o aumento da produtividade e qualidade. Esta ação produz resultados positivos, pois permite a redução dos custos e ainda aumenta a qualidade do serviço prestado, além de evitar o retrabalho, permitindo a boa utilização dos recursos disponíveis. Os indicadores de nível operacional têm com função avaliar se os processos (ponta a ponta), os subprocessos ou padrões individuais estão vinculados à melhoria contínua e à busca da excelência, alinhados à estratégia geral. Devem representar todos os processos existentes na empresa que sejam importantes na criação de valor para o cliente (FNQ, 2012).

\section{4- Perspectiva de Aprendizado e Crescimento}

a) $\mathrm{O}$ mundo corporativo vem passando por mudanças rápidas e profundas, exigindo cada vez mais profissionais de alto desempenho. Neste contexto, qual é a sua avaliação sobre o perfil do profissional de assessoria executiva?

\section{executiva)}

(Esta questão pode ser aplicada tanto para executivo, quanto para a assessora

A formação generalista destes profissionais, seu raciocínio lógico, sua capacidade de liderança e sua facilidade no gerenciamento de informações e, sobretudo, sua determinação e vontade de aprender (MEC, no 3, 2005), lhes confere empregabilidade em empresas de diferentes ramos de atuação, tornando-os aptos a se moldar e adquirir competências baseadas no setor em que atua ou até mesmo do nível hierárquico onde está inserido. É evidente que a valorização e desenvolvimento destas competências são fatores que melhoram a capacidade 
de atuação corporativa e a capacidade cognitiva dos colaboradores, potencializando o sucesso de ambos (RESENDE, 2003). Gramigna (2002) aborda a analogia do desenvolvimento de competências do indivíduo com o processo de crescimento de uma árvore. A raiz representa a atitude, sendo a soma dos valores, crenças e princípios acumulados durante a vida. A atitude é o ponto mais relevante na composição da competência, está ligado com "querer ser e querer agir". Conhecimento corresponde ao tronco da árvore, é o segundo fator. Na formação da competência, é o conjunto de informações que o indivíduo armazena e as emprega quando necessário, quanto maior esta capacidade, melhor será a flexibilidade e entendimento nas diversas situações do dia a dia. A copa com seus frutos, flores e folhas, remete às habilidades. A capacidade de agir com destreza, a técnica de realização, obtendo os resultados almejados. Em paralelo, o profissional de assessoria executiva desenvolve com maestria todas essas habilidades, atuando nos diversos níveis organizacionais. A organização necessita que as pessoas possuam habilidades e que respondam às expectativas estratégicas (BERGAMINI 2012).

b) Como você avalia o desempenho e aprimoramento, bem como as metas de crescimento, do profissional de assessoria na organização?

(Esta questão pode ser aplicada para o executivo)

c) Como você avalia o seu desempenho e aprimoramento, bem como suas metas de crescimento, na organização?

\section{(Esta questão pode ser aplicada para o profissional de assessoria executiva)}

Ainda existe uma lacuna nas empresas no que diz respeito à mensuração de desempenho dos profissionais de assessoria executiva. Em decorrência disto, há um movimento incipiente de profissionais da classe na busca pela transformação dessa realidade, uma vez que a inexistência de estudos específicos, bem como parâmetros para medir seus resultados, causa prejuízos em seu desempenho e desencadeia fatores negativos como: desmotivação, falta de efetividade e notoriedade de sua atuação no meio corporativo (D’ELIA, 2013). Porém, a importância de reverter esta lacuna está na afirmação de Kaplan e Norton (1997), que salientam que o intuito dos modelos de mensuração é motivar executivos e colaboradores a implementarem com êxito a estratégia do negócio. Desta forma, entendese que todos devem estar envolvidos nesta ação, pois sua implementação traz maior visibilidade dos objetivos a serem alcançados, além de envolver todos os departamentos da empresa na realização das metas estratégicas (MANICA et al., 2017).

\section{5- Mapa estratégico}

a) Com base no mapa estratégico, como esta ferramenta contribui para a compreensão dos indicadores de desempenho na organização e como o profissional de assessoria executiva está inserido nesse contexto?

(Esta questão pode ser aplicada tanto para o executivo, quanto para o profissional de assessoria executiva)

A função do mapa estratégico é fornecer os pilares para a construção do BSC conectado com a estratégia da organização (KAPLAN; NORTON, 2004b). Permite que todos na empresa aumentem sua compreensão acerca do negócio, ampliando seu entendimento da estratégia adotada pela empresa (KAPLAN; NORTON, 2004b). O mapa estratégico atua como um meio de comunicação e um sistema de informação, uma estrutura de constante 
aprendizado, bem como em uma fonte de motivação e alinhamento para os funcionários, que pode ser definido como a representação visual da história da estratégia de uma organização. Sua principal finalidade é descrever de forma clara como a empresa irá criar valor ao longo do tempo (HERRERO FILHO, 2005). O profissional de assessoria executiva, com seu perfil dinâmico e flexível, atua neste processo como agente facilitador, utilizando uma linguagem corporativa clara e objetiva, auxiliando a todos, uma vez que interage com profissionais de todos os níveis organizacionais (MARINHO, 2014).

\section{Contribuição Tecnológica/Social}

Este relato técnico busca, por meio de pesquisa bibliográfica, desenvolver uma sistemática para a implantação de indicadores de desempenho para a mensuração da produtividade dos profissionais de assessoria executiva, uma vez que é incipiente na literatura material específico sobre o tema.

A pesquisa revela a importância de as organizações traduzirem sua missão, visão, valores e cultura organizacional em objetivos estratégicos claros, transformando suas metas corporativas em tarefa de todos, envolvendo seus colaboradores e dando subsídios para que entendam o que se espera deles e como podem contribuir para o alcance de seus resultados. O simples ato de desenvolver indicadores gera um entendimento amplo da empresa, do ambiente corporativo e do mercado, sendo um importante passo rumo a melhoria do desempenho geral do negócio, além de promover uma negociação entre todos os envolvidos e permitir que a empresa identifique os problemas de todas ás ares que a compõe, e possa corrigi-los (KIYAN, 2001).

Neste contexto, o estudo propõe a utilização do BSC por ser uma ferramenta muito utilizada no meio corporativo e traduzir bem este objetivo. Aplicando-a no âmbito dos profissionais de assessoria executiva, transpondo uma linguagem subjetiva para uma linguagem objetiva, e evidenciando a importância do papel desenvolvido por este profissional.

Diante desta perspectiva, o profissional de assessoria executiva, com seu perfil eclético, vem desenvolvendo diferentes competências, impulsionados pela exigência do mercado e na ânsia de se adaptar às constantes mudanças organizacionais. Portanto, se faz necessário inseri-lo no cenário organizacional, traduzir suas atividades em medidas mensuráveis, fazendo com que o seu papel tenha visibilidade em sua área de atuação, para que possam contribuir no alcance dos resultados das organizações em que estão inseridos.

\section{Referências}

ASSIS, M. T. Indicadores de Gestão de Recursos Humanos: Usando indicadores demográficos, financeiros e de processos na Gestão do Capital Humano, Rio de Janeiro: Qualitymark, 2012.

BERGAMINI, C. W. Competência: a chave do desempenho. São Paulo: Atlas, 2012. 
BOOG, G. G.; BOOG, M. T. Manual de gestão de pessoas e equipes: estratégias e tendências. 6⿳亠丷厂 ed. São Paulo: Gente, 2002.

CAMPOS, L. M. S.; MELO, D. A; MEURER, S. A. A importância dos indicadores de desempenho ambiental nos sistemas de gestão ambiental (SGA). IX ENGEMA - Encontro Nacional sobre Gestão Empresarial e Meio Ambiente, Curitiba, 2007.

CARPINETTI, L. C. R. Gestão da Qualidade: conceitos e técnicas. 2ª ed. São Paulo: Atlas, 2012.

COSTA, A. P. P. D. Balanced Scorecard: conceitos e guia de implementação. São Paulo: Atlas, 2006.

D'ELIA, M. E. S.; AMORIM, M; SITA, M. (Orgs). Excelência no secretariado: a importância da profissão nos processos decisórios como assessorar e atingir resultados corporativos e pessoais com competência e equilíbrio. São Paulo: Ser Mais, 2013.

FATTAH, D.; SYARIPUDIN, M. A. Philosophical Business Performance Competition on the Balance Scorecard Approach. International Journal of Economic Persperctives, v. 10, n. 4, p. 541-551, 2016.

FERNADES, D. R. Uma contribuição sobre a construção de indicadores e sua importância para a gestão empresarial. Revista FAE, v. 7, n. 1, p. 1-18, 2004.

FLEURY, M. T. L; FLEURY, A. Estratégias empresariais e formação de competências: um quebra cabeça caleidoscópio da indústria brasileira. 3ํㅡㄹ ed. São Paulo: Atlas, 2007.

FRANCISCHINI, A. S. N.; FRANCISCHINI, P. G. Indicadores de Desempenho dos objetivos à ação - métodos para elaborar KPIs e obter resultados. Rio de Janeiro: Alta Books, 2017.

FUNDAÇÃO NACIONAL DE QUALIDADE (FNQ). Indicadores de Desempenho: Estruturação do Sistema de Indicadores Organizacionais. 3ª ed. São Paulo, 2012.

GRAMIGNA, M. R. M. Modelo de competências e gestão dos talentos. São Paulo: Pearson Makron Books, 2002.

GERLACH, F. R. Impactos do associativismo na pecuária leiteira paulista: Estudo de Casos - Dissertação (mestrado). Universidade Federal de São Carlos. 2004.

GIL, A. C. Como elaborar projetos de pesquisa. $4^{\underline{a}}$ ed. São Paulo: Atlas, 2007.

HERRERO FILHO, E. Balanced Scorecard e a gestão estratégica: uma abordagem prática. Rio de Janeiro: Elsevier, 2005.

KAPLAN, R. S.; NORTON, D. P. A estratégia em ação: Balanced Scorecard. Rio de Janeiro: Campus, 1997.

. Organização orientada para a estratégia: como as empresas que adotam o balanced scorecard prosperam no novo ambiente de negócios. 2. ed. Rio de Janeiro: Campus, 2001. 
Kaplan e Norton na prática. Rio de Janeiro: Elsevier, 2004a.

de Janeiro: Campus, 2004b.

KIYAN, F. M. Proposta para desenvolvimento de indicadores de desempenho como suporte estratégico. Dissertação (mestrado). Escola de Engenharia de São Carlos, Universidade de São Paulo. 2001.

MANICA, E. et al. Deployment of the balanced scorecard as a tool for measuring performance: Case of a technology company in Brazil. Business Management Dynamics, v. 7, n. 06, p. 08-18, 2017.

MARINHO, A. P. (Orgs). Competências especiais para o desenvolvimento contínuo do profissional de secretariado executivo. Ed. São Paulo: Sinsesp,

NEIVA, E. G.; D’ELIA, M. E. S. As novas competências do profissional de Secretariado. $2^{a}$ ed. São Paulo: IOB, 2009.

NIVEN, P. R. Balanced Scorecard passo-a-passo: elevando o desempenho e mantendo resultados. Rio de Janeiro: Qualitymark, 2005.

OLIVEIRA, H. M. C. The Balanced Scorecard Operating as a Risk Management Tool: Review of Economic Studies \& Research Virgil Madgearu, v. 7, n. 02, p. 42-57, 2014.

ONG, T. S. et al. Adoption and Implementation of Balanced Scorecard in Malaysia. AsiaPacific Management Accounting Journal, v. 5, n 1, p. 21-40, 2010.

RESENDE, E. O livro das competências: desenvolvimento das competências: a melhor autoajuda para pessoas, organizações e sociedade. 2ª ed. Rio de Janeiro: Qualitymark, 2003.

SEHIC-KRSLAK, S. Examples of good practice implementation of Balaced Scorecard BSC model. International May Conference on Strategic Management, Bor, Serbia, 2016. 